90:653-5

6. Heidenreich O, Tirtakusuma R, Bomken S, et al. The genomic landscape of lineage switch acute leukemia. Blood (ASH Annual Meeting Abstracts) 2013;122(Suppl):2552.

7. Jiang JG, Roman E, Nandula SV, Murty VV, Bhagat G, Alobeid B. Congenital MLL-positive B-cell acute lymphoblastic leukemia (B-ALL) switched lineage at relapse to acute myelocytic leukemia (AML) with persistent $t(4 ; 11)$ and $t(1 ; 6)$ translocations and JH gene rearrangement. Leuk Lymphoma 2005;46:1223-7.

8. Ruiz-Delgado GJ, Nuñez-Cortez AK, Olivares-Gazca JC, Fortiz YC, Ruiz-Argüelles A, Ruiz-Argüelles GJ. Lineage switch from acute lymphoblastic leukemia to myeloid leukemia. Med Univ 2017;19:27-31.

9. Aujla A, Hanmantgad M, Islam H, Shakil F, Liu D, Seiter K. Lineage switch from T-cell lymphoblastic leukemia/lymphoma to acute myeloid leukemia and back to T-cell lymphoblastic leukemia/lymphoma in a patient diagnosed during pregnancy. Stem Cell Investig 2019;6:12.

10. Ittel A, Jeandidier E, Helias C, et al. First description of the $\mathrm{t}(10 ; 11)(\mathrm{q} 22 ; \mathrm{q} 23) /$ MLL-TET1 translocation in a T-cell lymphoblastic lymphoma, with subsequent lineage switch to acute myelomonocytic myeloid leukemia. Haematologica 2013;98:e166-8.

11. Higuchi $Y$, Tokunaga $K$, Watanabe $Y$, et al. Lineage switch with $\mathrm{t}(6 ; 11)(\mathrm{q} 27 ; \mathrm{q} 23)$ from T-cell lymphoblastic lymphoma to acute monoblastic leukemia at relapse. Cancer Genet 2016;209:267-71.

12. Babić A, Kurić L, Dubravčić K, et al. A case of an unusual lineage switch in late relapse ALL-is it actually a secondary leukemia? J Hematop 2020;13:51-5.

13. Ganser A, Heuser M. Therapy-related myeloid neoplasms. Curr Opin Hematol 2017;24:152-8.

14. McNerney ME, Godley LA, Le Beau MM. Therapy-related myeloid neoplasms: when genetics and environment collide. Nat Rev Cancer 2017;17:513-27.

15. Ganzel C, Devlin S, Douer D, Rowe JM, Stein EM, Tallman MS. Secondary acute lymphoblastic leukaemia is constitutional and probably not related to prior therapy. Br J Haematol 2015;170: 50-5.

\section{Utility of platelet cross-matching in a case of neonatal alloimmune thrombocytopenia associated with a de novo MECOM variant}

TO THE EDITOR: Neonatal alloimmune thrombocytopenia (NAIT) is the most important cause of thrombocytopenia in term neonates. It was estimated to occur at a frequency of 1 in 1,000-2,000 live births [1]. Platelet destruction is caused by a maternal antibody directed against a fetal human platelet antigen (HPA) inherited from the father and lacking in the platelets of the mother. In the Caucasian population, $80 \%$ alloimmunization occurs predominantly due to antibodies to the HPA-1a antigen [1]. Although less common, the HPA-15 antigen system is also implicated in serologically confirmed NAIT cases [2]. The HPA-15a15b system is located on the glycosyl-phosphatidylinositol-anchored protein, CD109, and is defined by the single amino acid substitution of Ser703Tyr (Ser682Tyr of mature CD109 protein) [3]. The diagnosis of NAIT can be established by documenting the presence of a platelet-specific antigen incompatibility between mother and infant (or mother and father) and the presence of maternal antiplatelet allo-antibodies directed against the incompatible HPA antigen [4]. The monoclonal antibody-specific immobilization of platelet antigen (MAIPA) assay is considered as the 'gold-standard' test to detect maternal anti-HPA antibodies [4]. However, it is not available for routine use in India. Platelet cross-match, which is commonly used to provide platelet transfusion support in platelet refractoriness, may be considered as an alternative strategy to manage emergency cases of NAIT in resource-limited facilities where a platelet-donor registry is still unavailable [5].

In 2015, heterozygous mutations in the MECOM (MDS1 and EVI1 complex locus) were first identified as a cause of amegakaryocytic thrombocytopenia in neonates [6]. There are many novel mutations in the MECOM gene that have been identified recently, and a new name, 'MECOMassociated syndrome,' has been proposed for this disease [7]. Herein, we report a rare case of NAIT associated with HPA-15b incompatibility in a baby who was managed initially with the transfusion of cross-matched platelets, but due to persistent transfusion-dependent thrombocytopenia and inadequate response to appropriate therapy such as IVIG, whole exome sequencing was performed, which re-

Table 1. Platelet cross-match, platelet antibody screening and HPA genotyping results.

\begin{tabular}{|c|c|}
\hline Tests & Results \\
\hline $\begin{array}{l}\text { Platelet antibody screening with baby's } \\
\text { serum }\end{array}$ & Positive \\
\hline $\begin{array}{l}\text { Platelet antibody screening with } \\
\text { mother's serum }\end{array}$ & Positive \\
\hline $\begin{array}{l}\text { Mother's serum cross-matched with } \\
\text { baby's platelets }\end{array}$ & Incompatible \\
\hline $\begin{array}{l}\text { Mother's serum cross-matched with } \\
\text { husband's (father's) platelets }\end{array}$ & Incompatible \\
\hline $\begin{array}{l}\text { Baby's serum cross-matched with } \\
\text { father's platelets }\end{array}$ & Incompatible \\
\hline $\begin{array}{l}\text { Incompatibility \% during platelet } \\
\text { cross-matching: from day } 1 \text { to day } 20\end{array}$ & $50 \%(8 / 16)$ \\
\hline $\begin{array}{l}\text { Incompatibility \% during platelet } \\
\text { cross-matching: from day } 21 \text { to day } 40\end{array}$ & $30 \%(6 / 20)$ \\
\hline $\begin{array}{l}\text { Incompatibility \% during platelet } \\
\text { cross-matching: from day } 41 \text { to day } 61\end{array}$ & $18.2 \%(4 / 22)$ \\
\hline $\begin{array}{l}\text { HPA genotyping of baby and parents to } \\
\text { detect HPA incompatibility in the baby }\end{array}$ & $\begin{array}{l}\text { HPA-15b } \\
\text { incompatibility } \\
\text { detected in the baby }\end{array}$ \\
\hline
\end{tabular}

Abbreviation: HPA, human platelet antigen. 
vealed the presence of a de novo pathogenic MECOM variant.

A $2.69 \mathrm{~kg}$ male baby with a body surface area of $0.2 \mathrm{~m}^{2}$ was born through an elective cesarean section at term after an uneventful pregnancy in a tertiary care hospital. At birth, the baby was noted to have a few ecchymotic patches on the trunk. However, within a few hours, the baby became pale and soon developed multiple ecchymotic patches on the trunk, and had evidence of mucosal bleeds in the form of bloody gastro-intestinal aspirates and subconjunctival hemorrhages. There was no dysmorphism, microcephaly, or organomegaly. The baby was the firstborn child of a non-consanguineous couple with no family history of hematological disorders. The mother was healthy throughout the antenatal period with normal platelet counts and no features of connective tissue disease. She also had an intact spleen. There were no clinical or laboratory features of neonatal sepsis, intrauterine viral infections, or inherited syndromes in the baby. There was no abnormality detected in the coagulation profile on day 1 , the parameters of the liver function test were within their normal ranges, and ultrasound studies revealed no major internal hemorrhage. The platelet count was $8 \times 10^{9} / \mathrm{L}$, and the hemoglobin $(\mathrm{Hb})$ level was $10.1 \mathrm{~g} / \mathrm{dL}$ at first testing, although it plummeted to $4.4 \mathrm{~g} / \mathrm{dL}$ on day 2 because of bleeding. The blood group of the baby was ' $\mathrm{O}$ ' rhesus positive, mother was 'A' rhesus positive, and father was ' $O$ ' rhesus positive. On day 1 , the baby was transfused with $20 \mathrm{~mL} / \mathrm{kg} \mathrm{ABO}$-specific uncross-matched random donor platelets and administered $1 \mathrm{~g} / \mathrm{kg}$ of IVIG. The next day, the baby received $15 \mathrm{~mL} / \mathrm{kg}$
O-positive packed red cell transfusion due to low $\mathrm{Hb}$ levels. The platelet count improved to $135 \times 10^{9} / \mathrm{L}$ on day 2 but decreased gradually to $46 \times 10^{9} / \mathrm{L}$ on day 5 ; hence, a second dose of IVIG was administered. The platelet count decreased further to $20 \times 10^{9} / \mathrm{L}$ by day 7 without any bleeding manifestations; therefore, a further $0.4 \mathrm{~g} / \mathrm{kg}$ IVIG was administered. The baby's blood sample, along with the blood samples of his parents, was sent to a platelet serology laboratory, and another sample was sent for HPA genotyping of the baby and parents to detect HPA incompatibility. Table 1 summarizes all the results of platelet cross-matching, platelet antibody screening, and HPA genotyping. HPA genotyping was performed for HPA-1, 2, 3, 4, 5, 6, and 15 systems by DNA sequencing at the national referral laboratory. Platelet antibody testing was performed according to manufacturers' instructions using solid-phase adherence with an IgG platelet antibody detection and cross-match system (Capture-P, Immucor, Peachtree Corners, GA, USA), which utilizes fresh platelets bound to microplate wells from single group $\mathrm{O}$ donors [8]. There was no anti-HLA antibody detected in the mother when tested using Luminex technology. The chance of obtaining a compatible platelet unit for transfusion increased with the age of the baby, suggesting a gradual clearance of maternal-derived alloantibodies from the baby's circulation. All platelets that were administered for transfusion starting from day 7 were $\mathrm{O}$ group random donor cross-matched compatible platelets, leukodepleted, and irradiated. The $24 \mathrm{hr}$ corrected count increment (CCI) after transfusion of cross-matched platelets on day 7 , day

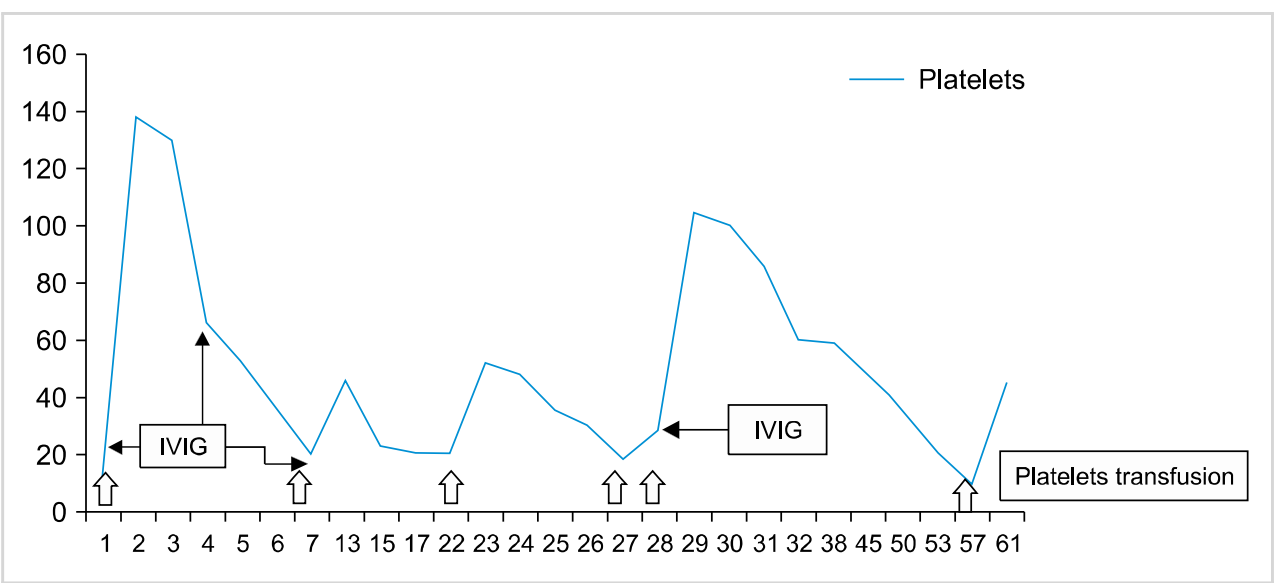

Fig. 1. Day-wise changes observed in platelet counts after transfusion of cross-matched platelets and IVIG.

Table 2. Whole exome sequencing results in baby.

\begin{tabular}{|c|c|c|c|c|c|c|c|}
\hline $\begin{array}{c}\text { Gene } \\
\text { (transcript) }\end{array}$ & Location & Variant & $\begin{array}{l}\text { Type of } \\
\text { mutation }\end{array}$ & Zygosity & Inheritance & $\begin{array}{l}\text { Disease } \\
\text { association }\end{array}$ & Pathogenicity \\
\hline $\begin{array}{l}\text { MECOM } \\
\text { (chr3:g.168806874_1 } \\
\text { 68806877delATTG) }\end{array}$ & Exon 16 & $\begin{array}{l}\text { c.3127_3130del } \\
\text { (p.Gln1043 } \\
\text { IlefsTer33) }\end{array}$ & $\begin{array}{l}\text { Deletion- } \\
\text { frameshift }\end{array}$ & Hetero-zygous & $\begin{array}{r}\text { Autosomal } \\
\text { dominant }\end{array}$ & $\begin{array}{l}\text { Radioulnar synostosis } \\
\text { with amegakaryocytic } \\
\text { thrombocytopenia-2 } \\
\text { (MECOM-associated } \\
\text { syndrome) }\end{array}$ & Pathogenic \\
\hline
\end{tabular}


23, and day 28 were 10000, 11667, and 13333, respectively. Fig. 1 shows the day-wise changes observed in the platelet counts. Because of the inadequate response to standard therapy for NAIT, such as IVIG, whole exome sequencing was performed after day 30, which revealed the presence of a pathogenic MECOM variant in the baby. No such mutation was found in parents, suggesting a de novo variant in this case. A heterozygous four-base pair deletion in exon 16 of the MECOM gene that results in a frameshift and premature truncation of the protein 33 amino acids downstream of codon 1043 was detected (Table 2). The p.Gln1043 IlefsTer33 variant has not been reported before in the 1000 genomes, gnom $\mathrm{AD}$, and internal databases. No skeletal abnormality was detected in this case. A bone marrow examination was performed before initiating a plan for allogeneic stem cell transplantation in this baby, which revealed a lack of megakaryocytes in the marrow. The risk of subsequent pregnancies and post-transfusion purpura in mothers was explained to the family in detail.

The most important lesson learned from this case is that the MECOM-associated syndrome does not rule out the presence of concomitant NAIT, as they are not mutually exclusive conditions. During platelet cross-matching, the incompatibility observed between the baby and the parents was the diagnostic pointer in this case, which raised the suspicion of NAIT even before the availability of HPA-genotyping results. The platelet serology results and HPA genotyping almost confirmed the HPA incompatibility in this case. A subsequent final confirmation by MAIPA could be the last step of the diagnostic algorithm; unfortunately, it could not be performed due to the unavailability of the assay. NAIT due to anti-HPA-15b incompatibility has never been reported in the Indian population. In NAIT, where HPA-15b is the only antibody involved, severe and persistent anemia can be detected without any evident etiology [9]. CD109 is also expressed on CD34+ progenitor cells, which might be a reason for thrombocytopenia and anemia in the presence of anti-HPA-15 antibodies [9]. Apart from cross-matched platelets, washed-irradiated maternal platelets might be another option for transfusion in NAIT cases where a platelet-donor registry is unavailable [4]. However, it was not considered in this case, as the mother was unable to move from the primary hospital due to the ongoing COVID-19 pandemic and lockdown crisis. Although it is recommended that transfusion should not be delayed in NAIT if the appropriate antigen-negative platelets are unobtainable $[4,10]$ cross-matched platelets might be considered a better alternative than routine random donor platelets. The platelet transfusion threshold, in this case, was in line with the BCSH guidelines [10]. Heterozygous mutations in the MECOM gene are associated with different clinical manifestations, starting from inherited bone marrow failure syndrome to skeletal abnormalities [7]. The reason for the excessive platelet transfusion requirement in this baby was finally understood during the course of the disease after the identification of the de novo MECOM variant.
Therefore, we conclude that in resource-limited settings, platelet cross-match might be considered as an alternative strategy for the diagnosis and management of NAIT cases until a specific diagnostic assay such as MAIPA or structured platelet-donor registry is available and the evaluation of MECOM variants by whole exome sequencing should be integrated into the diagnostic algorithm in cases of persistent transfusion-dependent neonatal thrombocytopenia.

Suvro Sankha Datta ${ }^{1}$, Sabita Basu ${ }^{1}$, Niharendu Ghara ${ }^{2}$, Pulak Kole ${ }^{3}$, Priti Khemka ${ }^{3}$

Departments of ${ }^{1}$ Transfusion Medicine and ${ }^{2}$ Pediatric Hematology, Tata Medical Center, Rajarhat, ${ }^{3}$ Department of Pediatrics and Neonatology, Bhagirathi Neotia Woman and Child Care Centre, Kolkata, India

Correspondence to: Suvro Sankha Datta Department of Transfusion Medicine, Tata Medical Center, Newtown, Rajarhat, Kolkata 700160, India E-mail: suvro.datta@gmail.com

Received on Nov. 27, 2020; Revised on Dec. 14, 2020; Accepted on Jan. 19, 2021 https://doi.org/10.5045/br.2021.2020299

\section{ACKNOWLEDGMENTS}

We are thankful to Dr. BP. Kulkarni from the NIIH, Mumbai, India for performing HPA genotyping and Medgenome laboratories, Bangalore, India for conducting whole exome sequencing.

\section{Authors' Disclosures of Potential Conflicts of Interest}

No potential conflicts of interest relevant to this article were reported.

\section{REFERENCES}

1. Kjeldsen-Kragh J, Killie MK, Tomter G, et al. A screening and intervention program aimed to reduce mortality and serious morbidity associated with severe neonatal alloimmune thrombocytopenia. Blood 2007;110:833-9.

2. Mandelbaum M, Koren D, Eichelberger B, Auerbach L, Panzer S. Frequencies of maternal platelet alloantibodies and autoantibodies in suspected fetal/neonatal alloimmune thrombocytopenia, with emphasis on human platelet antigen-15 alloimmunization. Vox Sang 2005;89:39-43.

3. Curtis BR, McFarland JG. Human platelet antigens - 2013. Vox Sang 2014;106:93-102.

4. Peterson JA, McFarland JG, Curtis BR, Aster RH. Neonatal alloimmune thrombocytopenia: pathogenesis, diagnosis and management. Br J Haematol 2013;161:3-14.

5. Venkatesh HA, Paul A, Kantharaj A, Chandrashekar S. A case report of neonatal alloimmune thrombocytopenia: the utility of platelet crossmatch studies in the diagnosis and management. Glob J Transfus Med 2019;4:234-6.

6. Niihori T, Ouchi-Uchiyama M, Sasahara Y, et al. Mutations in MECOM, encoding oncoprotein EVI1, cause radioulnar synos- 
tosis with amegakaryocytic thrombocytopenia. Am J Hum Genet 2015;97:848-54.

7. Germeshausen M, Ancliff P, Estrada J, et al. MECOM-associated syndrome: a heterogeneous inherited bone marrow failure syndrome with amegakaryocytic thrombocytopenia. Blood Adv 2018;2:586-96.

8. Juskewitch JE, Norgan AP, De Goey SR, et al. How do I $\cdots$ manage the platelet transfusion-refractory patient? Transfusion 2017;57: 2828-35.

9. Nogues N, Garcia A, Julia MR, et al. Anti-HPA15 (gov) antibodies detected in two cases of neonatal alloimmune trombocytopenia and in one case of immune refractoriness to platelet transfusion. Vox Sang 2006;91(Suppl 2):16-17.

10. Gibson BE, Todd A, Roberts I, et al. Transfusion guidelines for neonates and older children. Br J Haematol 2004;124:433-53.

\section{Coagulopathy profiles and their correlation with molecular viral burden in patients with COVID-19}

TO THE EDITOR: Viral infections cause coagulopathy by activating the coagulation cascade. Coagulopathy can result in thrombotic or hemorrhagic complications and plays a central role in determining prognosis [1]. Platelet numbers and functions are also affected during viral infections through various mechanisms. Viruses have been shown to induce thrombocytopenia by affecting platelet production and through peripheral destruction of platelets via specific glycoprotein antibodies [2].

Patients infected with severe acute respiratory syndrome coronavirus 2 (SARS-CoV-2) have shown intrinsic procoagulant effects and inflammatory responses [3]. The underlying mechanisms are still unclear, but apparently, the response against SARS-CoV-2 infection does not differ from infections with previously described coronaviruses [3]. Noticeable thrombotic phenomena with prolonged prothrombin time, activated partial thromboplastin time and increased D-dimer and fibrinogen concentrations have been observed in severe SARS-CoV-2 infections [4]. Here, we report the correlation between clinical coagulopathy profiles and SARS-CoV-2 viral load quantitated by real-time reverse transcriptase-polymerase chain reaction (RT-PCR) in patients with non-severe coronavirus disease 2019 (COVID-19).

A total of 24 patients diagnosed with SARS-CoV-2 infection using real-time RT-PCR were enrolled from February-July 2020 at the Chungbuk National University Hospital (CBNUH), a tertiary hospital in South Korea. Serial blood samples were obtained, and complete blood cell counts were measured using a Beckman DXH 800 (Beckman Coulter, Inc., Fullerton, CA, USA). Coagulation tests including prothrombin time (PT), activated partial thromboplastin time (aPTT), fibrinogen, fibrinogen degradation products (FDP), and D-dimer were performed using a Sysmex CS5100 automatic coagulation analyzer (Siemens Healthcare Diagnostics, Erlangen, Germany). Serial nasal and pharyngeal swabs and/or sputum samples were tested for SARS-CoV-2 using real-time RT-PCR (Allplex 2019-nCoV assay, Seegen, Seoul, Korea). A sample was considered SARS-CoV-2-positive when the $\mathrm{Ct}$ value for the three target genes $(E, R d R p$, and $N)$ was below 40 . The test results were considered inconclusive if one or two of the three genes showed $\mathrm{Ct}$ value below 40 for previously confirmed cases only. A sample was considered SARS-CoV-2-negative when the $\mathrm{Ct}$ value of the three target genes was above 40. Statistical analyses were performed using IBM SPSS Statistics (version 19.0, IBM Corp., Armonk, NY, USA). The Mann-Whitney test was used to analyze the variables between the two groups. Statistical significance was set at $P<0.05$.

Twenty-four patients presented to the CBNUH with confirmed SARS-CoV-2 infection. The median time interval from COVID-19 diagnosis to admission was 3.0 (0-18) days. All patients tested positive for SARS-CoV-2 by real-time RT-PCR. The median age of the cohorts was 55.5 (25-90 $\mathrm{yr})$, and $38 \%(\mathrm{~N}=9)$ were men. A total of 185 nasal and pharyngeal swabs and/or sputum samples were collected

Table 1. Clinical characteristics and laboratory findings in 24 patients diagnosed with COVID-19.

\begin{tabular}{|c|c|}
\hline Variable & Results \\
\hline Age $(y r)^{a)}$ & $55.5(25-90)$ \\
\hline Male sex $(\mathrm{N}, \%)$ & 9/24 (38\%) \\
\hline \multicolumn{2}{|l|}{ Combined disease } \\
\hline Hypertension & $3 / 24(13 \%)$ \\
\hline Diabetes & $4 / 24(17 \%)$ \\
\hline Chronic renal failure & $1 / 24(4 \%)$ \\
\hline $\begin{array}{l}\mathrm{N} \text { of days until molecular negative } \\
\text { conversion }^{\text {b) }}\end{array}$ & $30(16-40)$ \\
\hline \multicolumn{2}{|l|}{ Laboratory findings on admission day ${ }^{c}$} \\
\hline Hemoglobin (g/dL) & $13.1(10.1-16.1)$ \\
\hline White blood cells $\left(\times 10^{3} / \mu \mathrm{L}\right)$ & $4.30(2.24-7.44)$ \\
\hline Neutrophils $\left(\times 10^{3} / \mu \mathrm{L}\right)$ & $2.50(1.11-5.87)$ \\
\hline Lymphocytes $\left(\times 10^{3} / \mu \mathrm{L}\right)$ & $1.15(0.49-1.83)$ \\
\hline Platelets $\left(\times 10^{3} / \mu \mathrm{L}\right)$ & $206(107-554)$ \\
\hline Prothrombin time (INR) & $1.0(0.92-1.2)$ \\
\hline Activated partial thromboplastin time (s) & $29.1(21.7-34.2)$ \\
\hline $\begin{array}{l}\text { Peak fibrinogen }(\mathrm{mg} / \mathrm{dL}) \text { during } \\
\text { hospitalization }\end{array}$ & $482.4(230.4-863.2)$ \\
\hline $\begin{array}{l}\text { Peak D-dimer }(\mathrm{ng} / \mathrm{mL}) \text { during } \\
\text { hospitalization }\end{array}$ & $0.5(0.2-27.1)$ \\
\hline Peak CRP (mg/dL) during hospitalization & $2.9(0.1-17.8)$ \\
\hline Outcome: survival & $24 / 24(100 \%)$ \\
\hline \multicolumn{2}{|c|}{$\begin{array}{l}\text { a) Continuous value represent the median (min-max). }{ }^{\text {b) }} \text { Ten of the } \\
24 \text { patients were discharged after the asymptomatic period lasted } \\
\text { more than } 10 \text { days before the molecular negative conversion. } \\
\text { c) Complete blood count, prothrombin time, and activated partial } \\
\text { thromboplastic time results were described for } 20 \text { of the } 24 \\
\text { patients. The levels of fibrinogen, D-dimer, and CRP were } \\
\text { described in } 14,16 \text {, and } 22 \text { out of } 24 \text { patients, respectively. }\end{array}$} \\
\hline
\end{tabular}

